EXPERIMENTAL STUDY

\title{
Evaluation for roles of nitric oxide generated in the anteroventral third ventricular region in controlling vasopressin secretion and cardiovascular system of conscious rats
}

\author{
Ken'ichi Yamaguchi, Kazuo Watanabe ${ }^{1}$ and Kanemitsu Yamaya ${ }^{2}$ \\ Department of Physiology, Niigata University School of Medicine, Niigata, Japan, ${ }^{1}$ Department of Anatomy, Hamamatsu University School of \\ Medicine, Hamamatsu, Japan and ${ }^{2}$ Oyokyo Kidney Institute, Hirosaki, Japan \\ (Correspondence should be addressed to Dr Ken'ichi Yamaguchi, Department of Physiology, Niigata University School of Medicine, Asahimachi-Dori \\ 1-757, Niigata City, Niigata 951-8510, Japan)
}

\begin{abstract}
Objective: To examine local actions of nitric oxide (NO) on the neural mechanisms controlling the release of vasopressin (AVP) and the cardiovascular system in the anteroventral third ventricular region $(\mathrm{AV} 3 \mathrm{~V})$, a pivotal area for autonomic functions, and to pursue the problem of whether it may have any role in the AVP and cardiovascular responses evoked by plasma hypertonicity or by increased prostaglandin $\mathrm{E}_{2}\left(\mathrm{PGE}_{2}\right)$ in the $\mathrm{AV} 3 \mathrm{~V}$ - one possible factor implicated in osmotic responses.

Methods: We infused NO-related agents into the AV3V, its adjacent area, the nucleus of the vertical limb of the diagonal band (VDB), or into the lateral cerebral ventricle of conscious rats, monitoring effects on plasma AVP, osmolality, sodium, potassium and chloride, arterial pressure and heart rate in the presence or absence of an osmotic or $\mathrm{PGE}_{2}$ stimulus. The infusion sites were determined histologically.

Results: Infusion of L-arginine, the substrate of NO synthase (NOS), into the AV3V structures such as the median preoptic nucleus and periventricular nucleus produced dose-related increases in plasma AVP, arterial pressure and heart rate 5 or 15 min later, whereas infusion of D-arginine (which is not a substrate for NO synthesis) was without significant effect on these variables. Plasma osmolality or electrolytes were not changed by these treatments. The AV3V infusion of sodium nitroprusside (SNP), a spontaneous releaser of NO, also induced dose-dependent augmentations of plasma AVP, without evoking remarkable alteration in the cardiovascular parameters. The infusion of L- or D-arginine into the VDB affected none of the variables significantly. When applied intracerebroventricularly, Larginine caused only increases in plasma AVP, whereas SNP caused only reductions in arterial pressure, leaving other variables at stable values. The effects of AV3V L-arginine on plasma AVP and the cardiovascular variables were abolished by $N^{\mathrm{G}}$-nitro-L-arginine methyl ester (L-NAME), a potent inhibitor of NOS, applied $15 \mathrm{~min}$ before. In contrast, infusion of L-NAME to the AV3V did not exert a significant effect on the responses of plasma AVP or cardiovascular variables to AV3V application of $\mathrm{PGE}_{2}$ or i.v. infusion of hypertonic NaCl. The infusion of L-NAME alone did not affect plasma variables including AVP, although it tended to increase basal arterial pressure and heart rate.

Conclusion: These results suggest that NO generated in or near the AV3V may act to enhance AVP release, arterial pressure and heart rate, but it may not play an essential role in eliciting the responses of these variables to osmotic or $\mathrm{PGE}_{2}$ stimuli.
\end{abstract}

European Journal of Endocrinology 143 523-533

\section{Introduction}

Nitric oxide (NO) is a non-conventional neuromodulator produced from L-arginine by NO synthase (NOS) (1, $2)$. The presence of NOS in the paraventricular $(\mathrm{PVN})$ and supraoptic (SON) vasopressin (AVP) neurons and its increase in these neurons or the neurohypophysis by salt loading or dehydration suggest possible involvement of NO in regulating the secretion of AVP (3-5). However, the role of NO is not certain, as reflected by conflicting data obtained to date through both in vivo and in vitro studies (6-9). Such discrepancies could be 
explained by the possibility that NO may act at various cerebral sites to induce diverse effects, because NOS or its mRNA is distributed throughout the brain $(1,2)$. In order to understand roles of NO in the release of AVP and other phenomena, therefore, it seems necessary to clarify its actions on discrete regions exhibiting NOS activity.

Neurons in the PVN and SON are innervated by those in the anteroventral third ventricular region (AV3V), comprising structures such as the organum vasculosum laminae terminalis, periventricular preoptic nucleus, and the median and medial preoptic nuclei (10-12). The AV3V lacks a complete blood-brain barrier, shows sensitivity to various factors such as interleukin (IL)-1 $\beta$, prostaglandin (PG) $\mathrm{E}_{2}$ and hypertonicity (11-14), and participates in various autonomic functions, including AVP release, cardiovascular actions, febrile response and drinking behavior (10-12). In addition, histochemical studies have demonstrated the presence of NOS and its mRNA in AV3V neurons $(15,16)$. The possibility that NO formed in this region may have physiological significance has been suggested by the report that local application of L-arginine into the preoptic area (POA) changed the drinking behavior of rats (17). To our knowledge, however, roles of AV3V NO in controlling the release of AVP and the cardiovascular system have not yet been investigated.

We have recently indicated that stimulation of $\mathrm{PGE}_{2}$ receptors in the AV3V elicits AVP-releasing pressor and tachycardiac responses in rats, and AVP-releasing and pressor actions evoked by plasma hypertonicity may be mediated by $\mathrm{AV} 3 \mathrm{~V} \mathrm{PGE} 2(18,19)$. It is known that there may be a functional correlation between $\mathrm{PGE}_{2}$ and NO. For example, NO can activate cyclooxygenase to promote generation of $\mathrm{PGE}_{2}(20,21)$, and the febrile response to the application of $\mathrm{PGE}_{2}$ to the $\mathrm{POA}$ was blocked by an NOS inhibitor administered concomitantly (22). Therefore, if AV3V PGE 2 contributes to the AVP and pressor responses to the plasma hypertonicity, NO might also be implicated in these effects. In agreement with this view, Liu et al. (23) have reported that the intracerebroventricular (i.c.v.) injection of a potent NOS inhibitor $(24,25), N^{\mathrm{G}}$-nitro-L-arginine methyl ester (L-NAME) - a treatment that may allow the drug to act on the AV3V (26) - attenuated the effect of an osmotic stimulus on the water intake of rats. However, systemic infusion of L-NAME was without significant effect on osmotic AVP secretion in rabbits (27), and excitation of PVN neurons by i.c.v. IL-1 $\beta$ (which is capable of stimulating synthesis of both $\mathrm{PGE}_{2}$ (28) and NO $(29,30)$ ) was prevented not by L-NAME (31), but by a prostaglandin inhibitor (13). Accordingly, it may also be postulated that NO formed in the AV3V may not have a significant role in the AVP and cardiovascular responses to $\mathrm{PGE}_{2}$ or hyperosmolality.

The purpose of the present study was to examine the actions of $\mathrm{NO}$ on $\mathrm{AV} 3 \mathrm{~V}$ neural mechanisms for release of AVP and cardiovascular function, and to pursue the problem of whether NO generated in the AV3V may contribute to the AVP and cardiovascular responses to $\mathrm{PGE}_{2}$ and an osmotic load. In conscious rats, we first tested the effects of the infusion to the AV3V of L-arginine, its biologically inactive stereoisomer D-arginine and a spontaneous releaser of NO (32), sodium nitroprusside (SNP) on basal plasma AVP concentrations, osmolality, electrolytes, heart rate and arterial pressure. As these solutions were hypertonic, AV3V infusion of a hypertonic $\mathrm{NaCl}$ solution was also performed to compare effects. We then examined the influence of the AV3V administration of L-NAME on the responses of those variables to the application of L-arginine or $\mathrm{PGE}_{2}$ to the $\mathrm{AV} 3 \mathrm{~V}$ or the i.v. infusion of hypertonic $\mathrm{NaCl}$. Drugs administered into the AV3V may exert their effects by diffusion into the cerebral ventricle or adjacent tissue, therefore, we also studied the effects of administering the NO-related agents into the ventricle or the nucleus of the vertical limb of the diagonal band (VDB) containing NOS activity (1, $2,33)$.

\section{Materials and methods}

\section{Animals and surgery}

Wistar male rats weighing 300-360 g were anesthetized with pentobarbital sodium $(50 \mathrm{mg} / \mathrm{kg}$ i.p.) and placed in a stereotaxic apparatus (Type SR-6; Narishige, Tokyo, Japan). After a scalp incision was made, the lambda and bregma were located and the skull was leveled. A hole was drilled in the skull, and stainlesssteel guide cannulae of $0.5 \mathrm{~mm}$ outer diameter (Eicom, Kyoto, Japan) were lowered to just above the AV3V or VDB, or into a lateral cerebral ventricle. Coordinates of the tips were $0.3 \mathrm{~mm}$ posterior to the bregma, on the midline and $6.6 \mathrm{~mm}$ below the surface of the skull for AV $3 \mathrm{~V}$ cannulae, $0.7 \mathrm{~mm}$ anterior to the bregma, on the midline and $6.0 \mathrm{~mm}$ below the surface of the skull for VDB cannulae, and $0.8 \mathrm{~mm}$ posterior to the bregma, $1.5 \mathrm{~mm}$ right from the midline and $3.7 \mathrm{~mm}$ below the surface of the skull for the ventricular cannulae (34). The cannulae implanted were fixed on the skull with small screws and dental resin. After surgery, rats were injected i.m. with Penicillin G $(30000 \mathrm{U})$. The rats were kept in individual cages and food and water were available ad libitum.

Seven or 8 days after surgery, the rats were catheterized with PE-50 tubing in the left femoral artery and right jugular vein under ether anesthesia. When loading of hypertonic or isotonic saline was to be conducted, the left femoral vein was also catheterized with the tubing. The tubes were filled with heparinized saline $(240 \mathrm{U} / \mathrm{ml})$, sealed, exteriorized and secured at the back of the neck. In using the rats in the current study, we adhered to the Guiding Principles for the Care and Use of Animals approved by the Council of the Physiological Society of Japan. 


\section{Experiments}

Experiments were performed 1 or 2 days after the vascular catheterization mentioned above. The rats were transferred into individual plastic boxes $(8 \times 8 \times 25 \mathrm{~cm})$ that permitted them freedom of movement. After approximately $60 \mathrm{~min}$, the arterial line was connected to a disposable pressure transducer (Omeda, Tokyo, Japan) connected to an AP-600G amplifier (Nihon Kohden, Tokyo, Japan). Output signals from the amplifier were introduced to a personal computer system through a PowerLab/4s (AD Instruments Japan, Tokyo, Japan) and processed for electronic recordings and analyses of arterial pressure and heart rate. In parallel with the electronic recordings, signals of arterial pressure from the AP-600G amplifier and those of heart rate from an AT-601G pulse counter (Nihon Kohden) connected to the amplifier were recorded on paper charts, using an RTA-4100 recorder (Nihon Kohden). A preceding period of 30-60 min was necessary for these cardiovascular parameters to stabilize. The rats were then given one of the following treatments: [1] AV3V infusion of a $1 \mu \mathrm{l}$ solution containing $0,0.57(100 \mu \mathrm{g})$ or $1.3 \mu \mathrm{mol}(225 \mu \mathrm{g}) \mathrm{L}-$ or D-arginine; [2] AV $3 \mathrm{~V}$ infusion of $1 \mu \mathrm{l}$ isotonic saline $(0.15 \mathrm{~mol} / \mathrm{l})$ containing $0,0.08(25 \mu \mathrm{g}), 0.17(50 \mu \mathrm{g})$ or $0.34 \mu \mathrm{mol}(100 \mu \mathrm{g}) \mathrm{SNP}$ or infusion of $1 \mu \mathrm{l}$ hypertonic saline $(0.77 \mathrm{~mol} / \mathrm{l})$; [3] i.c.v. infusion of $1 \mu \mathrm{l}$ isotonic saline containing 0 or $0.34 \mu \mathrm{mol}$ SNP or infusion of the $1 \mu \mathrm{l}$ solution containing $1.3 \mu \mathrm{mol} \mathrm{L}$ - or D-arginine; [4] VDB infusion of $1 \mu \mathrm{l}$ isotonic saline or of the $1 \mu \mathrm{l}$ solution containing $1.3 \mu \mathrm{mol} \mathrm{L}$ - or D-arginine; [5] AV3V infusion of $1 \mu \mathrm{l}$ isotonic saline containing 0 or $0.74 \mu \mathrm{mol}(200 \mu \mathrm{g}) \mathrm{L}-\mathrm{NAME}$ and AV3V infusion of $1 \mu \mathrm{l}$ isotonic saline containing 0 or $12.8 \mathrm{nmol}(4.5 \mu \mathrm{g}) \mathrm{PGE}_{2}$, or infusion of the $1 \mu \mathrm{l}$ solution containing $1.3 \mu \mathrm{mol} \mathrm{L}-$ arginine; [6] AV3V infusion of $1 \mu \mathrm{l}$ isotonic saline containing 0 or $0.74 \mu \mathrm{mol}$ L-NAME and i.v. infusion of isotonic or hypertonic $(2.5 \mathrm{~mol} / \mathrm{l})$ saline. Time intervals between the first and second $A V 3 V$ infusions in treatment [5] were $15 \mathrm{~min}$, and those between the AV $3 \mathrm{~V}$ infusion and the onset of the i.v. infusion in treatment [6] were $10 \mathrm{~min}$.

The intracranial infusion was carried out at a rate of $1 \mu \mathrm{l} / \mathrm{min}$ for $1 \mathrm{~min}$, using 30 gauge stainless-steel tubing that protruded $1.0 \mathrm{~mm}$ (for AV3V and VDB infusion) or $0.3 \mathrm{~mm}$ (for i.c.v. infusion) beyond the ends of the guide cannulae and was connected to a microsyringe via polyethylene tubing. Approximately $1 \mathrm{~min}$ elapsed before the infusion tubing was withdrawn, to permit movement of drug away from its tip. The i.v. infusion was conducted at a rate of $0.1 \mathrm{ml} / \mathrm{kg}$ per min for $30 \mathrm{~min}$ through the femoral venous line. For these intracranial and i.v. infusions, a Harvard pump (model 11, South Natick, MA, USA) was used.

In rats undergoing treatments [1] to [4], blood samplings were conducted $5 \mathrm{~min}$ before and $5 \mathrm{~min}$ and $15 \mathrm{~min}$ after the intracranial infusion. A $3 \mathrm{ml}$ blood sample was taken from the femoral arterial line over a 30-s period during which $3 \mathrm{ml}$ of donor blood was returned through the jugular venous line. In rats undergoing treatments [5] and [6], the first blood samples were obtained, as described above, $10 \mathrm{~min}$ after the AV3V infusion of L-NAME or vehicle, at a time corresponding to $5 \mathrm{~min}$ before the second AV3V infusion or to $0 \mathrm{~min}$ before the i.v. infusion. Further blood samples were taken $5 \mathrm{~min}$ and $15 \mathrm{~min}$ after the second AV3V infusion, or $15 \mathrm{~min}$ and $30 \mathrm{~min}$ after the onset of the i.v. infusion. The donor blood was prepared on the day of experiment by collection (into a heparinized beaker (150 U/rat)) of the trunk blood issuing after decapitation of normal rats anesthetized lightly with diethyl ether.

The blood samples were divided into two fractions immediately after collection. A $2 \mathrm{ml}$ aliquot was mixed with $100 \mu \mathrm{l}$ of a solution containing $125 \mathrm{mmol} / \mathrm{l}$ disodium EDTA and $25 \mathrm{mmol} / \mathrm{l} o$-phenanthroline for subsequent measurements of plasma AVP. The remaining blood was used to check plasma osmolality and electrolytes. The separation of plasmas was performed by centrifugation at $2500 \mathrm{~g}$ at $2{ }^{\circ} \mathrm{C}$ for $15 \mathrm{~min}$. The plasma samples were stored at $-25^{\circ} \mathrm{C}$ until required for use.

\section{Chemicals}

L-Arginine and L-NAME hydrochloride were purchased from Research Biochemicals International (Natick, MA, USA). D-Arginine and SNP were obtained, respectively, from Wako Pure Chemical (Osaka, Japan) and Sigma (St Louis, MO, USA). $\mathrm{PGE}_{2}$ was kindly supplied by Ono Pharmaceutical (Osaka, Japan). Solutions of L- and Darginine were prepared as follows: $174 \mathrm{mg}$ or $435 \mathrm{mg}$ were added, respectively, to $750 \mu \mathrm{l}$ or $1000 \mu \mathrm{l} 0.9 \%$ $\mathrm{NaCl}$, followed by the addition of $1000 \mu \mathrm{l} 1 \mathrm{~mol} / \mathrm{l} \mathrm{HCl}$ or $945 \mu \mathrm{l} 2.5 \mathrm{~mol} / \mathrm{l} \mathrm{HCl}$ respectively. The $\mathrm{HCl}$ rendered the arginines soluble and neutralized the solutions to $\mathrm{pH}$ 7.4-7.7. SNP and $\mathrm{PGE}_{2}$ were dissolved in $0.9 \%$ $\mathrm{NaCl}$. All drug solutions were freshly made on the day of the experiments. The doses of $\mathrm{L}-\mathrm{NAME}$ and $\mathrm{PGE}_{2}$ used in this study were selected by reference to previous reports $(16,18,19,23,35)$.

\section{Histological analyses}

After each experiment was terminated, the rats were killed by i.v. injection of a lethal dose of pentobarbital sodium. Trypan blue solution (2\%) was administered i.c.v. or into the $\mathrm{AV} 3 \mathrm{~V}$ or $\mathrm{VDB}$, utilizing the same infusion tubing as used for the experiments. The brain was removed. The validity of the i.c.v. infusion performed during the experiments was confirmed by cutting the brain manually and inspecting the spread of the dye in the ventricular system. When infusion sites in the AV3V and VDB were to be examined, the brains were kept in $10 \%$ formalin solution for at least 2 weeks. 

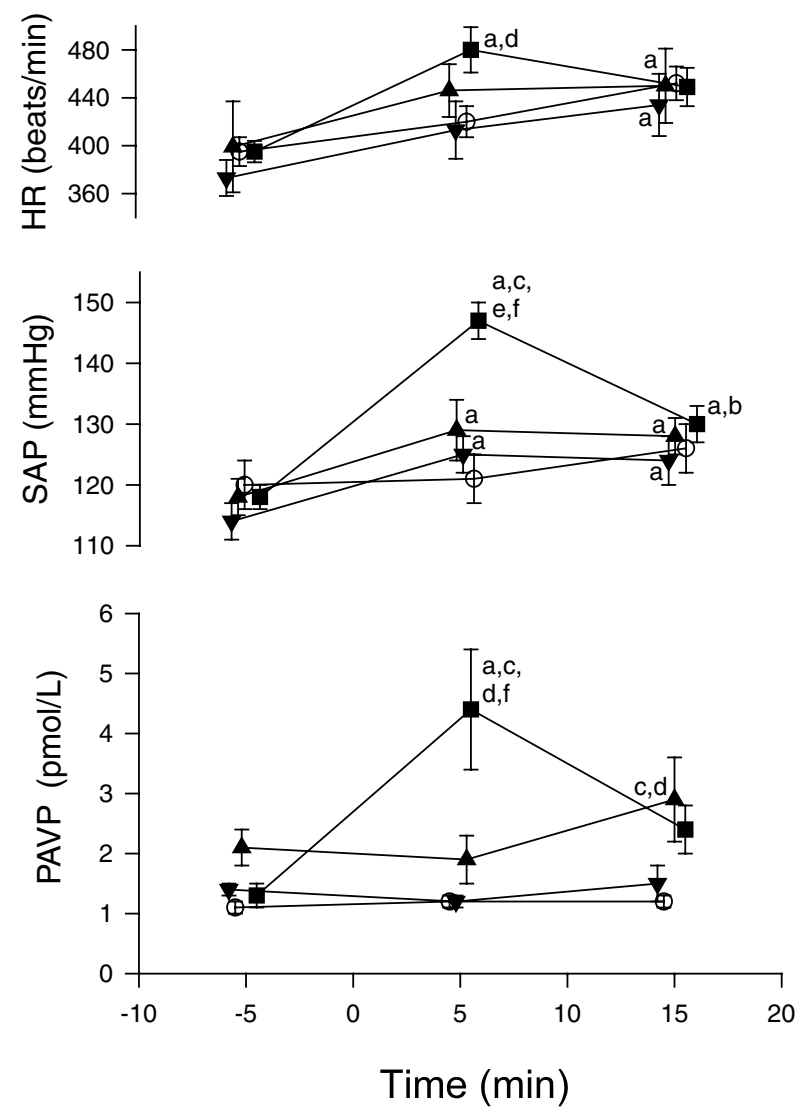

Figure 1 Effects of topical infusion of L-arginine $0.6 \mu \mathrm{mol}(\boldsymbol{\Delta}, n=4)$ or $1.3 \mu \mathrm{mol}(\boldsymbol{\square}, n=5)$, D-arginine $1.3 \mu \mathrm{mol}(\boldsymbol{\nabla}, n=8)$, or isotonic saline $(\bigcirc, n=9)$ into the AV3V on plasma AVP (PAVP), systolic arterial pressure (SAP) and heart rate (HR). Each solution $(1.0 \mu \mathrm{l})$ was infused over a period of $1 \mathrm{~min}$ from -1 to $0 \mathrm{~min}$. SAP and HR were measured every $30 \mathrm{~s}$, and averaged for 5 -min periods preceding blood samplings at $-5,5$ and $15 \mathrm{~min}$ for determinations of plasma variables, including AVP. a $P<0.05$ compared with $-5 \mathrm{~min} ;{ }^{\mathrm{b}} P<0.05$ compared with $5 \mathrm{~min} ;{ }^{\mathrm{c}} P<0.01$ compared with saline (O); ${ }^{d} P<0.05,{ }^{e} P<0.01$ compared with group receiving $1.3 \mu \mathrm{mol} \mathrm{D}$-arginine $(\boldsymbol{\nabla}) ;{ }^{\mathrm{f}} P<0.01$ compared with group receiving $0.6 \mu \mathrm{mol}$ L-arginine $(\boldsymbol{\Delta})$.

Afterwards, serial coronal sections of approximately $40 \mu \mathrm{m}$ thickness were cut with a freezing microtome. The sections were mounted on glass slides and stained with $0.1 \%$ cresyl violet. The infusion sites were judged according to the tissue injury made by the tubing, using the brain atlas (34) as a reference.

\section{Measurements}

Plasma AVP was extracted with acetone and petroleum ether and determined by radioimmunoassay. Synthetic $\left[\mathrm{Arg}^{8}\right]$ vasopressin (Protein Research Foundation, Osaka, Japan) was used as the reference standard. Tracer-labelled $\left[{ }^{125} \mathrm{I}\right]$ AVP was supplied from Mitsubishi Kagaku (Tokyo, Japan). The assay procedures have been described in detail elsewhere (36). Briefly, cross-reaction of the AVP antiserum with AVP-related peptides such as lysine vasopressin, arginine vasotocin, deamino-D-AVP and oxytocin was respectively $3.2 \times 10^{-1} \%, 8.9 \times$ $10^{-3} \%, 2.6 \times 10^{-2} \%$ and less than $5.9 \times 10^{-6} \%$. The recoveries (means \pm S.D.) of synthetic $\left[\mathrm{Arg}^{8}\right]$ vasopressin added to a plasma pool were $57.2 \pm 7.4 \%(n=10)$ at doses of $1.8-3.6 \mathrm{pmol} / \mathrm{l}$ and $54.3 \pm 6.4 \%$ at doses of $9.1-36.4 \mathrm{pmol} / \mathrm{l}(n=30)$. The values given for plasma AVP were corrected for losses during the extraction, with a mean recovery of $55.8 \%$. The within- and between-assay coefficients of variation for AVP assay were 10.1 and $13.9 \%$ respectively. The lower limit of detection of the AVP assay was $0.46 \mathrm{pmol} / \mathrm{l}$.

Plasma osmolality was estimated by freezing-point depression (Dai-ichi Kagaku OM-6040, Kyoto, Japan). Plasma sodium and potassium were determined by flame photometry (Hitachi 775-A, Tokyo, Japan), and plasma chloride, by electrometric titration (Hiranuma CL-7, Tokyo, Japan). Systolic arterial pressure and heart rate were measured every $30 \mathrm{~s}$ from electronic or paper records, and averaged for 5-min periods preceding blood samplings.

\section{Statistics}

All data are expressed as means \pm s.E.M. Within-group comparisons were carried out using a one-way analysis of variance (ANOVA) with repeated measures (5\% level of significance), unless stated otherwise. Between-group comparisons were performed using a two-way ANOVA ( $5 \%$ level of significance). Subsequently to these analyses, comparisons of means were conducted by Scheffe's F-test and by Duncan's multiple-range test respectively to detect statistically significant withingroup and between-group differences.

\section{Results}

\section{Effects of $A V 3 V$ infusion}

AV3V infusion of isotonic saline did not significantly affect plasma AVP, osmolality, sodium, potassium and chloride, arterial pressure or heart rate throughout the experiments (Fig. 1). The infusion of $0.6 \mu \mathrm{mol}$ L-arginine tended to increase slightly the plasma AVP, arterial pressure and heart rate 5 or $15 \mathrm{~min}$ later, whereas infusion of $1.3 \mu \mathrm{mol}$ L-arginine led to prominent augmentations in these variables, peak responses appearing at $5 \mathrm{~min}$ (Fig. 1). The values of these variables $5 \mathrm{~min}$ after the administration of $1.3 \mu \mathrm{mol}$ L-arginine were significantly greater than those observed in the group infused with the same dose of D-arginine. Although the infusion of D-arginine caused small increases in arterial pressure and heart rate, the values of these variables were not significantly different from those of the group receiving isotonic saline infusion. The administrations of L- or D-arginine did not change plasma osmolality, sodium, potassium or 


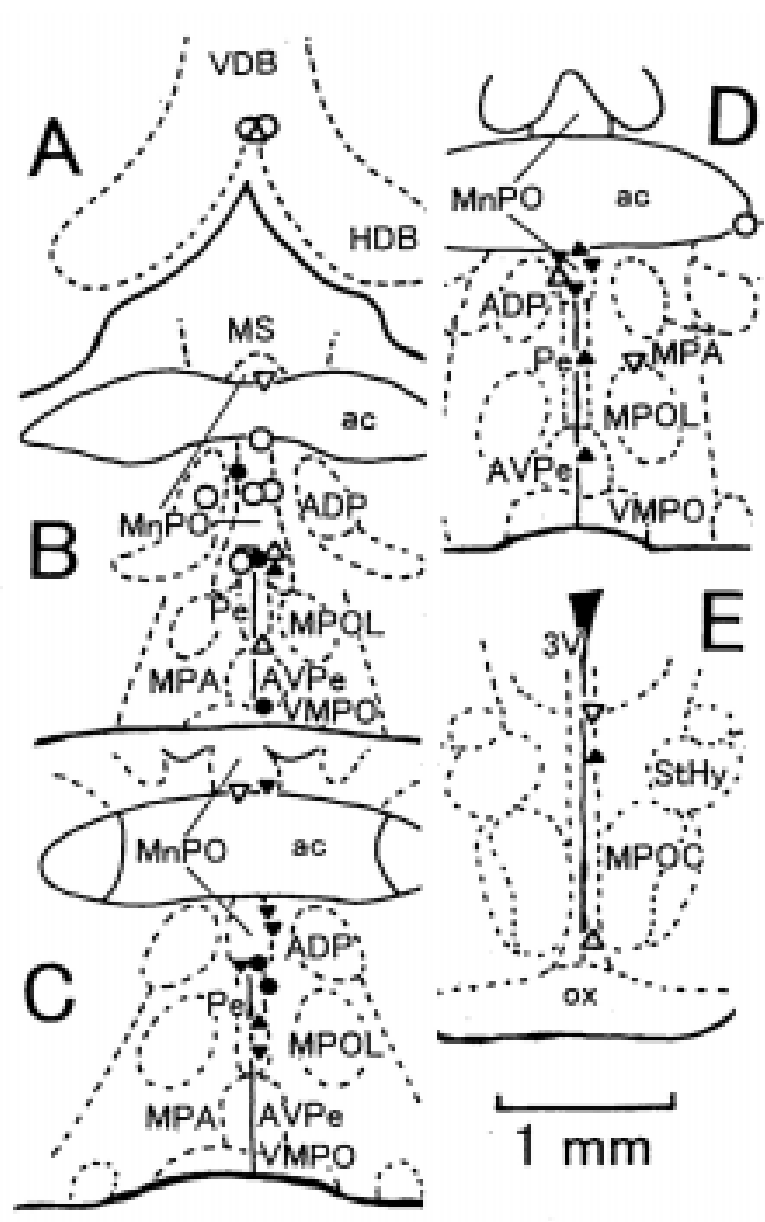

Figure 2 Infusion sites in the AV3V of L-arginine $1.3 \mu \mathrm{mol}(\bullet, n=5)$, D- arginine $1.3 \mu \mathrm{mol}(\mathrm{O}, n=8)$, SNP $168 \mathrm{nmol}(\triangle, n=5)$ or $336 \mathrm{nmol}$ $(\Lambda, n=6)$, hypertonic saline $770 \mathrm{mmol} / \mathrm{l}(\nabla, n=5)$ and $\mathrm{PGE}_{2}$ $(12.8 \mathrm{nmol}(\boldsymbol{\nabla}, n=8)$. Panels A-E correspond to coronal brain sections at distances from the bregma of $+0.2,-0.26,-0.3,-0.4$ and $-0.8 \mathrm{~mm}$ respectively. $3 \mathrm{~V}$, 3rd ventricle; ac, anterior commissure; ADP, anterodorsal preoptic nucleus; AVPe, anteroventral periventricular nucleus; HDB, nucleus of the horizontal limb of the diagonal band; MPOL, medial preoptic nucleus, lateral part; MnPO, median preoptic nucleus; MPA, medial preoptic area; MPOC, medial preoptic nucleus, central part; MS, medial septal nucleus; ox, optic chiasm; $\mathrm{Pe}$, periventricular hypothalamic nucleus; StHy, striohypothalamic nucleus; VDB, nucleus of the vertical limb of the diagonal band; VMPO, ventromedial preoptic nucleus.

chloride significantly. Infusion sites of $1.3 \mu \mathrm{mol} \mathrm{L-}$ or D-arginine in these rats included the median preoptic nucleus, medial POA, periventricular nucleus, anteroventral periventricular nucleus, ventromedial preoptic nucleus and anterodorsal preoptic nucleus (Fig. 2).

The ability of $1.3 \mu \mathrm{mol}$ L-arginine to enhance plasma AVP, arterial pressure and heart rate was also evident in rats receiving pre-administration of isotonic saline, the vehicle for L-NAME, $15 \mathrm{~min}$ before the arginine. When $0.74 \mu \mathrm{mol}$ L-NAME was pre-administered, however, the effects of L-arginine were abolished and the values for plasma AVP, arterial pressure and heart rate detected at

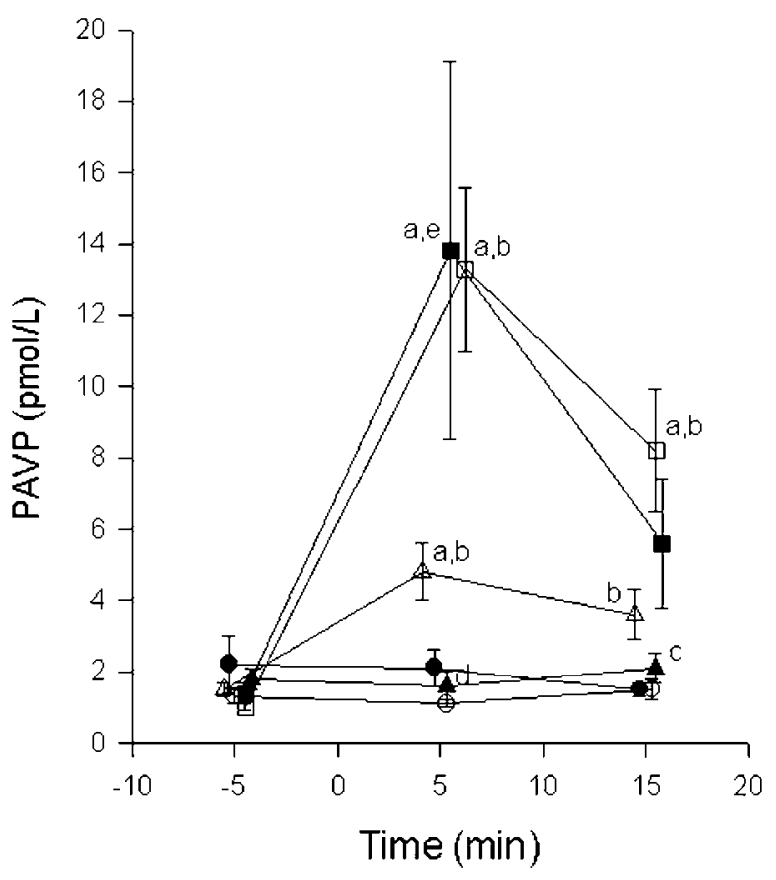

Figure 3 Effects of pre-administration of L-NAME on the plasma AVP (PAVP) response to AV3V infusion of L-arginine or $\mathrm{PGE}_{2}$. The first infusion $(1.0 \mu \mathrm{l})$ of $0.74 \mu \mathrm{mol}$ L-NAME or saline and the second infusion $(1.0 \mu \mathrm{l})$ of $1.3 \mu \mathrm{mol}$ L- arginine, $12.8 \mathrm{nmol}^{\mathrm{PGE}_{2}}$ or saline were conducted over 1 -min periods from -16 to -15 min and from -1 to 0 min respectively. $\bigcirc$, saline+saline $(n=10) ; \Delta$, saline + L-arginine $(n=6) ; \square$, saline $+\mathrm{PGE}_{2}(n=8) ; \bullet$, L-NAME + saline $(n=4) ; \boldsymbol{\square}$, L-NAME $+\mathrm{PGE}_{2}(n=6) ; \boldsymbol{\Delta}$, L-NAME + L-arginine $(n=5)$. ${ }^{\text {a }} P<0.05$ compared with $-5 \mathrm{~min}$; ${ }^{\mathrm{b}} P<0.01$ compared with saline + saline $(O) ;{ }^{\mathrm{c}} P<0.05,{ }^{\mathrm{d}} P<0.01$ compared with saline + L-arginine $(\triangle) ;{ }^{e} P<0.01$ compared with L-NAME + saline $(\bullet)$.

5 or 15 min were not statistically different from those in the group receiving L-NAME and isotonic saline (Fig. 3, Table 1). The infusion sites of L-NAME and L-arginine in these rats were identified in the median preoptic nucleus, medial POA and periventricular nucleus.

The AV3V infusion of SNP resulted in dose-dependent increases in plasma AVP, with maximal responses at 5 min (Fig. 4). Plasma osmolality, sodium, potassium and chloride were not affected significantly. In some SNP groups, arterial pressure or heart rate at $15 \mathrm{~min}$ were slightly but significantly greater than the respective basal values at $-5 \mathrm{~min}$ (Table 2 ). However, these values were not statistically different from those of the vehicle group, except for heart rate at $15 \mathrm{~min}$ in the group receiving $336 \mathrm{nmol} \mathrm{SNP}$. It was verified that infusion sites of SNP in these rats had been in the median preoptic nucleus, periventricular nucleus and medial POA (Fig. 2).

When the AV3V sites depicted in Fig. 2 were infused with $1 \mu \mathrm{l}$ hypertonic saline (770 mmol/l, $1540 \mathrm{mosmol} /$ $\mathrm{kg}$ ), the sodium concentration of which was equal to and the osmolality of which was relatively large compared with that of the solution containing 
Table 1 Cardiovascular parameters in the rats for which plasma AVP responses are shown in Fig. 3.

\begin{tabular}{|c|c|c|c|c|c|c|}
\hline \multirow[b]{2}{*}{ Group } & \multicolumn{3}{|c|}{ Systolic arterial pressure $(\mathrm{mmHg})$} & \multicolumn{3}{|c|}{ Heart rate (beats/min) } \\
\hline & $-5 \min$ & $5 \min$ & $15 \mathrm{~min}$ & $-5 \min$ & $5 \mathrm{~min}$ & $15 \mathrm{~min}$ \\
\hline $\begin{array}{l}\mathrm{SAL}+\mathrm{SAL}(n=10) \\
\mathrm{SAL}+\mathrm{L}-\mathrm{ARG}(n=6) \\
\mathrm{SAL}+\mathrm{PGE}_{2}(n=8) \\
\text { L-NAME + SAL }(n=4) \\
\text { L-NAME + L-ARG }(n=5) \\
\text { L-NAME + PGE } 2(n=6)\end{array}$ & $\begin{array}{l}115 \pm 3 \\
121 \pm 3 \\
113 \pm 3 \\
130 \pm 2^{d} \\
130 \pm 5 \\
124 \pm 4\end{array}$ & $\begin{array}{l}121 \pm 4 \\
143 \pm 3^{\mathrm{a}, \mathrm{d}} \\
141 \pm 3^{\mathrm{a}, \mathrm{d}} \\
133 \pm 3 \\
136 \pm 3 \\
141 \pm 5^{\mathrm{a}}\end{array}$ & $\begin{array}{l}115 \pm 4 \\
132 \pm 3^{\mathrm{d}} \\
147 \pm 4^{\mathrm{a}, \mathrm{d}} \\
127 \pm 3^{\mathrm{c}} \\
135 \pm 4 \\
155 \pm 4^{\mathrm{a}, \mathrm{b}, \mathrm{e}}\end{array}$ & $\begin{array}{l}377 \pm 21 \\
396 \pm 10 \\
383 \pm 11 \\
470 \pm 11^{d} \\
437 \pm 7 \\
448 \pm 31\end{array}$ & $\begin{array}{l}414 \pm 26 \\
452 \pm 21^{\mathrm{a}} \\
523 \pm 29^{\mathrm{a}, \mathrm{c}} \\
460 \pm 13 \\
455 \pm 10 \\
511 \pm 25\end{array}$ & $\begin{array}{l}403 \pm 29 \\
433 \pm 12 \\
474 \pm 24^{\mathrm{a}, \mathrm{c}} \\
466 \pm 25^{\mathrm{c}} \\
454 \pm 13 \\
514 \pm 17\end{array}$ \\
\hline
\end{tabular}

SAL, saline; L-ARG, L-arginine.

${ }^{a} P<0.05$ compared with $-5 \mathrm{~min} ;{ }^{\mathrm{b}} P<0.05$ compared with $5 \mathrm{~min} ;{ }^{\mathrm{c}} P<0.05,{ }^{\mathrm{d}} P<0.01$ compared with $\mathrm{SAL}+\mathrm{SAL} ;{ }^{\mathrm{e}} P<0.01$ compared with L-NAME + SAL.

$336 \mathrm{nmol} \mathrm{SNP}$ in $1 \mu \mathrm{l}(770 \mathrm{mmol} / \mathrm{l}, 1172 \mathrm{mosmol} / \mathrm{kg})$, plasma AVP increased significantly 5 and 15 min later. However, the responses were fairly small relative to those elicited by the administraion of $336 \mathrm{nmol} \mathrm{SNP}$ (Fig. 4). The infusion of hypertonic saline also caused a pressor response (Table 2), whereas plasma osmolality and electrolytes remained unchanged.

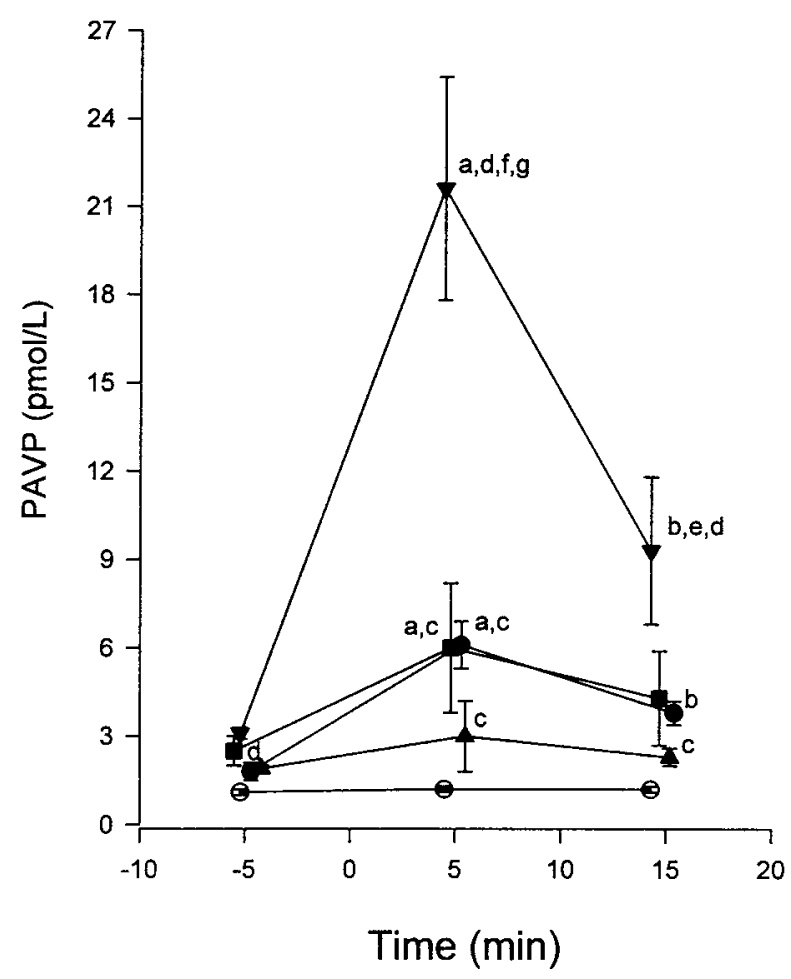

Figure 4 Effects of AV3V infusion of SNP $84 \mathrm{nmol}(\boldsymbol{\Lambda}, n=6)$, $168 \mathrm{nmol}(\boldsymbol{\square}, n=5)$ or $336 \mathrm{nmol}(\mathbf{\nabla}, n=6)$, or isotonic $(O, n=9)$ or hypertonic $(\bullet, n=5)$ saline on plasma AVP (PAVP). Each solution $(1.0 \mu \mathrm{l})$ was infused over a period of $1 \mathrm{~min}$ from -1 to $0 \mathrm{~min}$. ${ }^{\mathrm{a}} P<0.05$ compared with $-5 \mathrm{~min} ;{ }^{\mathrm{b}} P<0.05$ compared with $5 \mathrm{~min}$; ${ }^{\mathrm{c}} P<0.05,{ }^{\mathrm{d}} P<0.01$ compared with isotonic saline $(0)$; ${ }^{\mathrm{e}} P<0.05$, ${ }^{\mathrm{f}} P<0.01$ compared with hypertonic saline $(\bullet) ;{ }^{9} P<0.01$ compared with group receiving $168 \mathrm{nmol}$ SNP $(\mathbf{\square})$.

\section{Effects of i.c.v. infusion}

Administration of $1.3 \mu \mathrm{mol}$ L-arginine into the lateral cerebral ventricle caused AVP-increasing responses (Fig. 5). Although the arterial pressure was slightly increased $5 \mathrm{~min}$ later, the values were not statistically different from those of the D-arginine group, and were significantly smaller $(P<0.05)$ than those of the group given $1.3 \mu \mathrm{mol}$ L-arginine into the AV3V (Fig. 1). The i.c.v. infusion of L-arginine did not exert a significant effect on heart rate, plasma osmolality, sodium, potassium or chloride. In the group receiving D-arginine i.c.v., all the monitored variables remained unaltered. I.c.v. application of $336 \mathrm{nmol}$ SNP elicited a depressor response 5 min later, without changing plasma AVP and other variables. These effects of SNP on plasma AVP and arterial pressure were different from those evoked by its application to the AV3V.

\section{Effects of VDB infusion}

After the VDB application of $1.3 \mu \mathrm{mol}$ L-arginine, slight increases were observed in arterial pressure and heart rate. Values of these variables, however, were similar to those in the D-arginine group (Fig. 6). Plasma AVP, osmolality and electrolytes did not change after the application of the two agents. The infusion sites of $\mathrm{L}-$ and D-arginine were verified to have been situated in the areas of the VDB and medial septum, distances of which from the bregma ranged from 0.2 to $1.0 \mathrm{~mm}$, according to the brain atlas of Paxinos \& Watson (34).

\section{Effects of $\mathrm{PGE}_{2}$ and hyperosmolality in the presence or absence of $\mathrm{L}$-NAME}

In rats receiving pre-administration of vehicle, infusion of $\mathrm{PGE}_{2}$ into the median preoptic nucleus and periventricular nucleus (Fig. 2) led to marked increases in plasma AVP, arterial pressure and heart rate, without affecting plasma osmolality, sodium, potassium and chloride. Such responses of plasma AVP and arterial pressure were not altered by the pre-administration of L-NAME (Fig. 3, Table 1). Although increases in heart 
Table 2 Cardiovascular parameters in the rats for which plasma AVP responses are shown in Fig. 4.

\begin{tabular}{|c|c|c|c|c|c|c|}
\hline \multirow[b]{2}{*}{ Group } & \multicolumn{3}{|c|}{ Systolic arterial pressure $(\mathrm{mmHg})$} & \multicolumn{3}{|c|}{ Heart rate (beats/min) } \\
\hline & $-5 \min$ & $5 \min$ & $15 \min$ & $-5 \min$ & $5 \min$ & $15 \min$ \\
\hline $\operatorname{SAL}(n=9)$ & $120 \pm 4$ & $121 \pm 4$ & $126 \pm 4$ & $395 \pm 12$ & $420 \pm 13$ & $452 \pm 14$ \\
\hline HT-SAL $(n=5)$ & $116 \pm 4$ & $135 \pm 2^{a, c}$ & $130 \pm 4^{a}$ & $379 \pm 16$ & $405 \pm 7$ & $433 \pm 16^{a}$ \\
\hline SNP $(84 \mathrm{nmol})(n=6)$ & $123 \pm 5$ & $129 \pm 4$ & $133 \pm 3$ & $390 \pm 8$ & $425 \pm 13$ & $441 \pm 27^{a, b}$ \\
\hline SNP $(168 \mathrm{nmol})(n=5)$ & $119 \pm 4$ & $118 \pm 3$ & $129 \pm 6^{a, b}$ & $410 \pm 13$ & $439 \pm 14$ & $457 \pm 20^{a}$ \\
\hline SNP $(336 \mathrm{nmol})(n=6)$ & $121 \pm 4$ & $117 \pm 4^{d}$ & $129 \pm 5^{b}$ & $385 \pm 11$ & $414 \pm 24$ & $393 \pm 24^{c}$ \\
\hline
\end{tabular}

SAL, saline; HT-SAL, hypertonic saline.

a $P<0.05$ compared with $-5 \mathrm{~min} ;{ }^{\mathrm{b}} P<0.05$ compared with $5 \mathrm{~min}$; ${ }^{\mathrm{c}} P<0.05$ compared with $\mathrm{SAL}$; ${ }^{\mathrm{d}} P<0.05$ compared with $\mathrm{HT}-\mathrm{SAL}$.

rate induced by $\mathrm{PGE}_{2}$ were rendered insignificant $(P>0.05)$ by L-NAME treatment - possibly because of an increase in its basal value at $-5 \mathrm{~min}-$ the values at 5 and $15 \mathrm{~min}$ were similar to those of the group receiving vehicle plus $\mathrm{PGE}_{2}$ (Table 1 ).

The i.v. infusion of isotonic saline in rats receiving AV3V infusion of vehicle did not significantly affect any of the variables monitored. This was also the case when
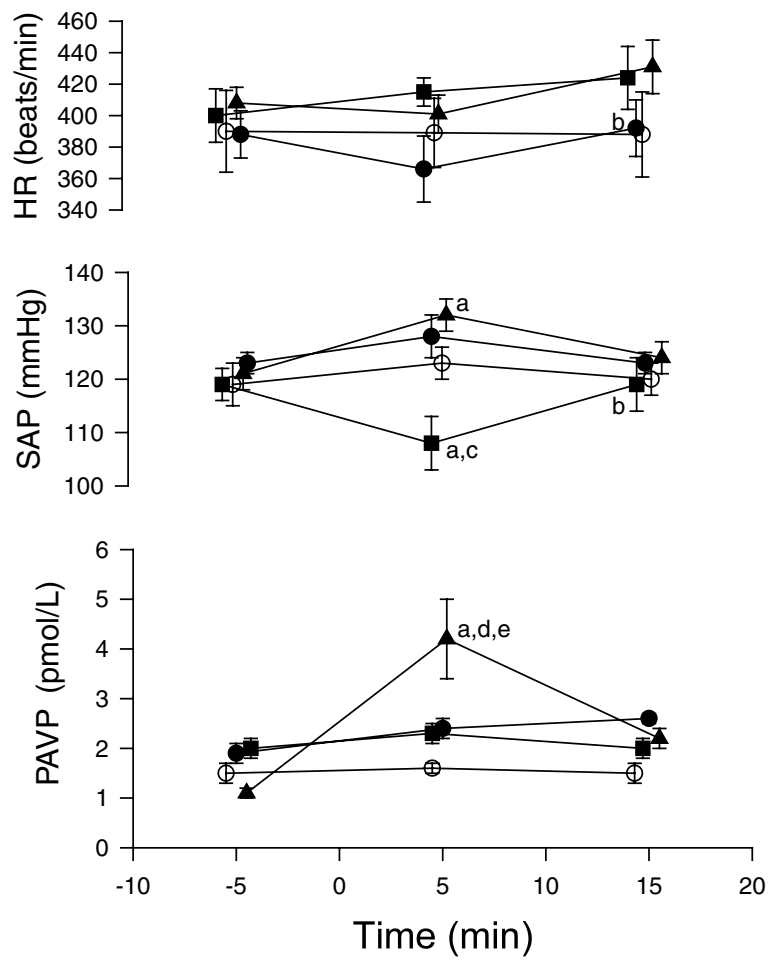

Figure 5 Effects of i.c.v. infusion of L-arginine $1.3 \mu \mathrm{mol}(\boldsymbol{\Delta}, n=6)$, D-arginine $1.3 \mu \mathrm{mol}(\bullet, n=3)$, SNP $336 \mathrm{nmol}(\boldsymbol{\square}, n=4)$, or saline $(\bigcirc, n=5)$ on plasma AVP (PAVP), systolic arterial pressure (SAP) and heart rate $(\mathrm{HR})$. Each solution $(1.0 \mu \mathrm{l})$ was infused over a period of $1 \mathrm{~min}$ from -1 to $0 \mathrm{~min}$. SAP and $\mathrm{HR}$ were measured every $30 \mathrm{~s}$, and averaged for 5-min periods preceding blood samplings at $-5,5$ and 15 min for determinations of plasma variables, including AVP. ${ }^{\mathrm{a}} P<0.05$ compared with $-5 \mathrm{~min} ;{ }^{\mathrm{b}} P<0.05$ compared with $5 \mathrm{~min}$;

${ }^{\mathrm{c}} P<0.05,{ }^{\mathrm{d}} P<0.01$ compared with saline $(O)$; ${ }^{\mathrm{e}} P<0.01$ compared with D-arginine ( $\square)$.
L-NAME was administered into the AV3V before the infusion of isotonic saline (Fig. 7).

When hypertonic saline was infused i.v. after AV3V administration of vehicle, plasma AVP augmented progressively, in parallel with increases in plasma osmolality, sodium and chloride (Fig. 7). Plasma concentrations of sodium at 0,15 and $30 \mathrm{~min}$ were $139.6 \pm 0.7 \mathrm{mmol} / \mathrm{l}, \quad 147.4 \pm 0.9 \mathrm{mmol} / \mathrm{l} \quad(P<$ 0.01 compared with $0 \mathrm{~min}$ or i.v. isotonic saline infusion $(142.8 \pm 0.9 \mathrm{mmol} / \mathrm{l}))$ and $151.0 \pm 1.0 \mathrm{mmol} / \mathrm{l}$

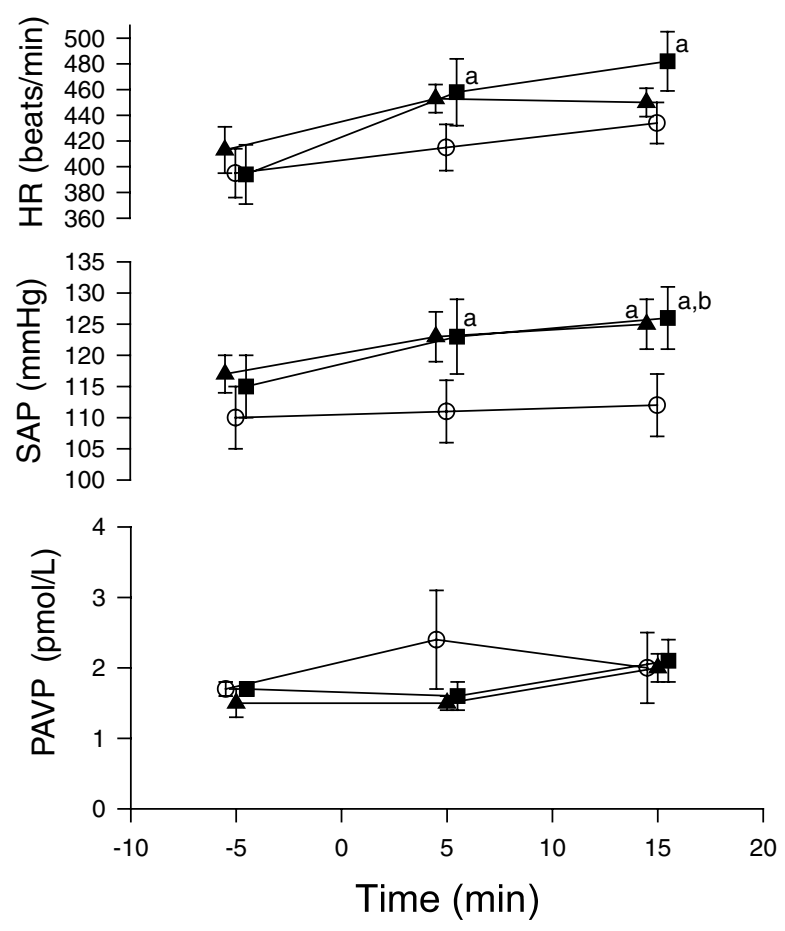

Figure 6 Effects on plasma AVP (PAVP), systolic arterial pressure (SAP) and heart rate (HR) of the topical infusion of L-arginine $1.3 \mu \mathrm{mol}(\boldsymbol{\square}, n=6)$, D-arginine $1.3 \mu \mathrm{mol}(\boldsymbol{\Lambda}, n=5)$, or saline $(\mathrm{O}$, $n=4$ ) into the nucleus of the vertical limb of the diagonal band. Each solution $(1.0 \mu \mathrm{l})$ was infused over a period of $1 \mathrm{~min}$ from -1 to $0 \mathrm{~min}$. SAP and HR were measured every $30 \mathrm{~s}$, and averaged for 5-min periods preceding blood samplings at $-5,5$ and $15 \mathrm{~min}$ for determinations of plasma variables, including AVP. ${ }^{\mathrm{a}} P<0.05$ compared with $-5 \mathrm{~min} ;{ }^{\mathrm{b}} P<0.05$ compared with saline $(O)$. 


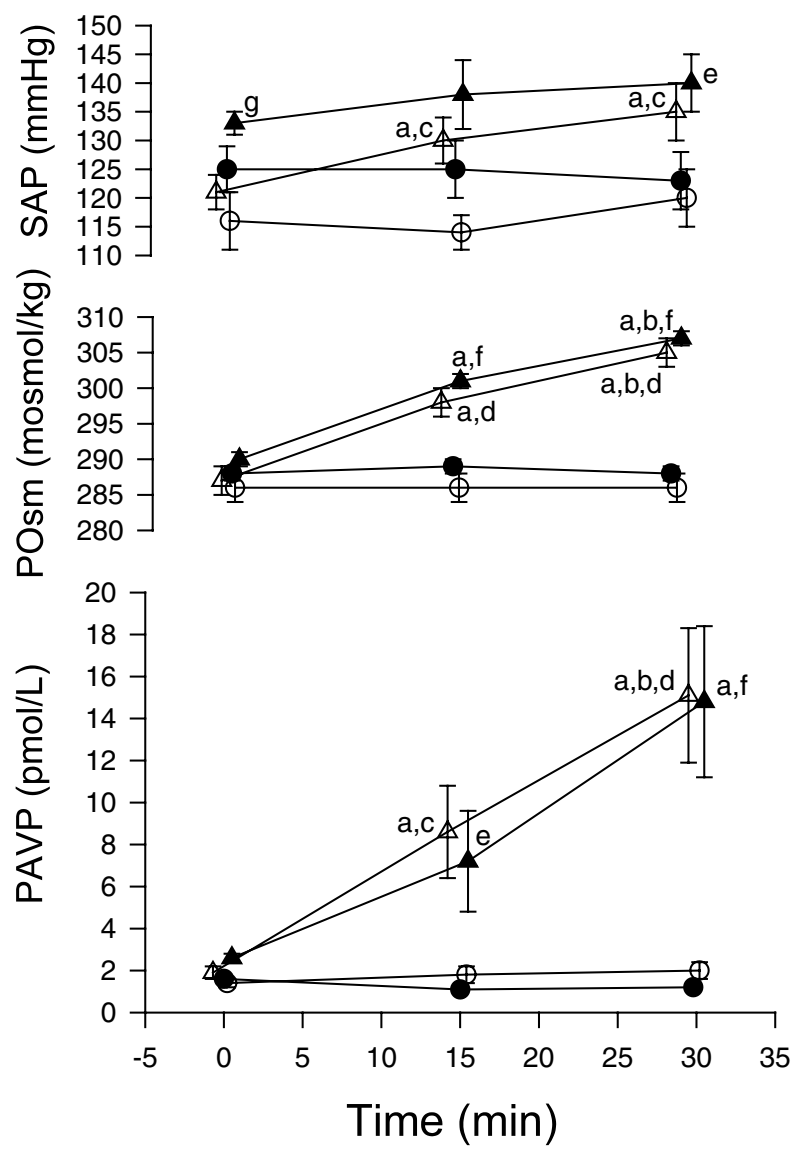

Figure 7 Effects of AV3V infusion of L-NAME on the responses of plasma AVP (PAVP), plasma osmolality (POsm) and systolic arterial pressure (SAP) to the i.v. infusion of saline $0.15 \mathrm{~mol} / \mathrm{l}$ or hypertonic saline $2.5 \mathrm{~mol} / \mathrm{l}$. L-NAME $0.74 \mu \mathrm{mol}$ or its vehicle (saline) was infused $(1 \mu \mathrm{l})$ over a period of $1 \mathrm{~min}$ from -11 to $-10 \mathrm{~min}$ preceding the i.v. infusion $(0.1 \mathrm{ml} / \mathrm{kg}$ body weight per $\mathrm{min}$ ) of saline or hypertonic saline started at $0 \mathrm{~min} .{ }^{\mathrm{a}} P<0.01$ compared with $0 \mathrm{~min}$ ${ }^{\mathrm{b}} P<0.05$ compared with $15 \mathrm{~min} ;{ }^{\mathrm{c}} P<0.05,{ }^{\mathrm{d}} P<0.01$ compared with saline AV3V + saline i.v. $(O, n=5) ;{ }^{\mathrm{e}} P<0.05,{ }^{\mathrm{f}} P<0.01$ compared with L-NAME AV3V + saline i.v. $(\bullet, n=5) ;{ }^{9} P<0.05$ compared with saline AV3V+hypertonic saline i.v. $(\triangle, n=8)$. $\mathbf{\Lambda}$, L-NAME $\mathrm{AV} 3 \mathrm{~V}+$ hypertonic saline i.v. $(n=6)$.

$(P<0.01$ compared with 0 min or i.v. isotonic saline infusion $(142.8 \pm 1.1 \mathrm{mmol} / \mathrm{l}))$ respectively, and those of chloride at 0,15 and $30 \mathrm{~min}$ were $99.8 \pm 1.0 \mathrm{mmol} /$ $\mathrm{l}, 108.1 \pm 0.9 \mathrm{mmol} / \mathrm{l}(P<0.01$ compared with $0 \mathrm{~min}$ or i.v. isotonic saline infusion $(101.0 \pm 1.7 \mathrm{mmol} / \mathrm{l}))$ and $111.1 \pm 0.7 \mathrm{mmol} / \mathrm{l} \quad(P<0.01$ compared with $0 \mathrm{~min}$ or i.v. isotonic saline infusion (100.3 \pm $1.8 \mathrm{mmol} / \mathrm{l})$ ) respectively. Arterial pressure was also enhanced by hypertonic saline (Fig. 7), whereas significant alteration was not caused in heart rate or plasma potassium $(P>0.05)$. AV $3 \mathrm{~V}$ application of L-NAME for which infusion sites had been located in the median preoptic nucleus and periventricular nucleus did not influence the responses of plasma AVP, osmolality and electrolytes to the osmotic load (Fig. 7).
Although the pressor action of hypertonic saline was not significant $(P>0.05)$ after the L-NAME treatment, it was noticed that basal arterial pressure at 0 min was significantly large in comparison with that of the group infused with vehicle before the osmotic load, the phenomenon by which the pressor action might have been obscured.

As mentioned above, AV3V administration of L-NAME tended to increase basal levels of arterial pressure and heart rate. When the data at $-5 \mathrm{~min}$ in Table 1 and 0 min in Fig. 7 were analyzed collectively because they reflected the values $10 \mathrm{~min}$ after the L-NAME treatment, basal arterial pressure and heart rate were $120 \pm 2 \mathrm{mmHg}$ (pre-infusion value $121 \pm 2 \mathrm{mmHg}$ ) and $400 \pm 5$ beats/min (pre-infusion value $397 \pm 7$ beats/min) respectively, in rats given vehicle infusion, and $128 \pm 2 \mathrm{mmHg}(P<0.01$ compared with preinfusion value $(118 \pm 1 \mathrm{mmHg})$ by paired $t$-test or compared with vehicle group by Duncan's test) and $437 \pm 8$ beats/min $(P<0.01$ compared with preinfusion level $(397 \pm 6$ beats/min) or vehicle group), respectively, in rats given L-NAME infusion.

\section{Discussion}

Over recent years, histochemical studies have demonstrated the existence of NOS in neural cell bodies and fibers of the AV3V $(15,16)$, the region important for autonomic functions (10-12). However, the physiological significance of $\mathrm{NO}$ generated in this area has scarcely been investigated yet, despite various observations suggesting significant roles of cerebral NO in controlling autonomic functions $(1,2)$. The present study was undertaken to explore roles of AV3V NO in AVP secretion and cardiovascular function in the presence or absence of an osmotic stimulus or its related factor, $\mathrm{PGE}_{2}(18,37)$.

We demonstrated that $\mathrm{AV} 3 \mathrm{~V}$ application of L-arginine augmented plasma AVP, arterial pressure and heart rate in basal conditions (Fig. 1). The effects on the first two variables were the same as those induced by i.c.v. application of this agent (9), supporting the view that action sites of drugs given into the cerebral ventricle may include the AV3V (26). As the increase in plasma AVP appeared shortly after the L-arginine infusion in the absence of AVP-releasing factors such as increased plasma osmolality or sodium and reduction of blood pressure, it may be attributable to the ability of the agent to promote AVP secretion. The solution containing L-arginine at the dose of $1.3 \mu \mathrm{mol}$ in $1 \mu \mathrm{l}$ showed hyperosmolality of about $1.8 \mathrm{osmol} / \mathrm{kg}$. Because AVPreleasing mechanisms in the $\mathrm{AV} 3 \mathrm{~V}$ possess osmo- or sodium-sensitivity (38), as we verified in the present study (Fig. 4), it could be argued that the AVPenhancing ability of the AV3V infusion of L-arginine may have been due to the hyperosmolality of the solution. However, substances such as L-arginine that are capable of easily penetrating the cell membrane are 
known to be ineffective as osmotic stimuli (39). In fact, AV $3 \mathrm{~V}$ infusion of the D-arginine solution $(1.3 \mu \mathrm{mol}$ in $\mathrm{l} \mu \mathrm{l}$ ), which had the same osmolality as the L-arginine solution and which cannot be used for NO synthesis, was not able to increase plasma AVP or the cardiovascular variables (Fig. 1). Moreover, the responses of these variables to AV3V L-arginine were abolished by the potent NOS inhibitor, L-NAME (25). Considering the current results together with the presence of NOS or its mRNA in the AV3V $(15,16)$, it seems that NO synthesized from L-arginine may have been responsible for the AVP-enhancing, pressor and tachycardiac effects evoked by the AV3V infusion of the agent. This idea is supported in part by the result obtained with SNP, the drug capable of generating NO without depending on NOS activity (32): AV3V infusion of the SNP solution ( $336 \mathrm{nmol}$ in $\mathrm{l} \mu \mathrm{l}$ ) resulted in remarkable augmentation of plasma AVP, and the AVP response was markedly large compared with that elicited by the administration of hypertonic $\mathrm{NaCl}(770 \mathrm{nmol}$ in $\mathrm{l} \mu \mathrm{l})$, the osmolality of which was relatively greater and the sodium concentration of which was equal (Fig. 4). The AVP-releasing activity of SNP has also been reported by an in vitro study using a brain slice preparation (7). Unlike the effects of AV3V L-arginine, AV3V SNP did not cause conspicuous pressor and tachycardiac actions (Table 2). Although the reason for this discrepancy is not certain, differences in the sites and periods of generation of $\mathrm{NO}$ (40) may be indicated, in addition to a possible influence of the cyanate moiety of SNP.

The VDB is also known to contain NOS activity $(1,2$, 33). This region is adjacent to the AV $3 \mathrm{~V}$ and may be involved in the regulation of the release of AVP associated with blood pressure changes (41). Therefore, it could be suspected that L-arginine applied into the AV $3 \mathrm{~V}$ might have diffused into this area to elicit the effects. However, infusion of L-arginine into the VDB affected none of the variables monitored (Fig. 6). This result makes such a possibility unlikely and suggests a negligible role of VDB NO in controlling the release of AVP or the cardiovascular system. Conversely, the fact that an AVP-enhancing effect was brought about not only by AV3V L-arginine but also by i.c.v. L-arginine might arouse a suspicion that the agent given into the AV $3 \mathrm{~V}$ diffused into the ventricular system to produce an AVP-releasing effect through actions on other periventricular areas. It seems certain, however, that the AV3V possesses AVP-releasing mechanisms sensitive to NO, because the effect of SNP on AVP was observed only when it was applied into the AV3V (Fig. 4). L-Arginine did not induce pressor or tachycardiac effects in the case of the i.c.v. infusion. Therefore, it seems reasonable to speculate that the AVP and cardiovascular responses to

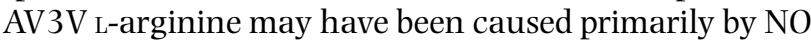
action on the AV3V.

The AV3V neurons receive afferent inputs arising from the brainstem catecholaminergic neurons, and innervate neurons in the PVN and SON that send axons to the neurohypophysis and brainstem cardiovascular areas, in addition to those in the parabrachial nucleus and mesencephalic central gray $(11,12,42-44)$. NO has been demonstrated to potentiate basal and evoked release of dopamine, noradrenaline and acetylcholine from presynaptic nerve endings in several brain regions (45); these are the neurotransmitters capable of inducing AVP release and pressor action when liberated into the AV3V or i.c.v. (46-50). Glutamate release may also be potentiated by NO (51). In addition, NO is known to function as one mediator in intracellular signaling pathways triggered by stimulation of $N$-methyl-D-aspartate, $\alpha$-adrenergic or cholinergic receptors that have been shown to reside in the AV $3 \mathrm{~V}$ $(20,24,52)$. Taken together, these observations could be presumed to indicate that NO generated from L-arginine or SNP given into the AV3V may have exerted the cardiovascular and pituitary effects by affecting release of those neurotransmitters or intracellular events triggered by them.

We have confirmed our previous finding that AV3V infusion of $\mathrm{PGE}_{2}$ leads to remarkable increases in plasma AVP, arterial pressure and heart rate (Fig. 3, Table 1). It is probable that $\mathrm{PGE}_{2}$ receptors in the AV3V may have been responsible for these phenomena, because they are abundant in this region (14) and the agent applied into the i.c.v. or the neighboring structures such as the medial septal nucleus, anterior commissure or VDB were not effective (50). The effects of the prostanoid were not affected significantly by pretreatment with L-NAME (Fig. 3, Table 1). This result is in agreement with the data that excitation of PVN neurons in response to a stimulus (IL-1 $\beta$ ), the effect of which may be dependent on stimulation of $\mathrm{PGE}_{2}$ synthesis in periventricular areas, was not influenced by i.c.v. L-NAME (31). The possibility that the dose of L-NAME used may have been large enough to inhibit NOS activity is suggested by the current observation that the treatment with L-NAME abolished the AV3V actions of L-arginine, and by previous reports that the drug injected centrally at doses similar to those we used brought about maximal inhibition of NOS activity over a 6-h period (25) and prevented hypotension-evoked AVP secretion throughout a 30-min experimental period (35). Therefore, it appears that NOS in the AV3V may not be involved in the AVP and cardiovascular responses to $\mathrm{PGE}_{2}$. Although POA application of L-NAME has been reported to block the febrile response to $\mathrm{PGE}_{2}$ (22), cerebral mechanisms underlying the thermogenic action of $\mathrm{PGE}_{2}$ may be different from those implicated in the AVP and cardiovascular responses to the prostanoid. Similarly, AV3V application of L-NAME was without significant effect on the responses of AVP and arterial pressure to i.v. infusion of hypertonic saline (Fig. 7). This result supports the observation of Goyer et al. (27) that L-NAME infused into the peripheral circulation because of its ability to cross the blood-brain barrier (25) did not alter such responses in rabbits. The 
fact that the AV3V infusion of L-NAME influenced neither the effects of plasma hypertonicity nor those of $\mathrm{PGE}_{2}$, one cerebral factor engaged in the osmotic responses $(18,37)$, suggests that NOS activity in the AV $3 \mathrm{~V}$ may not have an essential role in regulating AVP release and arterial pressure in the hyperosmotic state. In contrast to this view, Liu et al. (23) have reported inhibition of osmotic drinking by i.c.v. L-NAME, suggesting a possible role of periventricular NOS activity in the osmosensitivity. However, those investigators did not locate the sites of action of this drug.

In conclusion, we suggest that NO synthesized in the AV3V may not be implicated in the AVP-releasing and cardiovascular responses to $\mathrm{AV} 3 \mathrm{~V} \mathrm{PGE}_{2}$ or plasma hyperosmolality, despite its potential to facilitate hormone secretion and cause pressor and tachycardiac actions. At present, the physiological role of AV3V NO remains obscure. To clarify this problem, further studies are necessary.

\section{Acknowledgements}

We wish to express our sincere appreciation to Mr Mamoru Koike (Kido Hospital, Niigata, Japan) for skilful measurements of plasma osmolality and electrolytes. We are also indebted to MitsubishiKagaku Corporation (Tokyo, Japan) and Ono Pharmaceutical Corporation (Osaka, Japan) for generous gifts of AVP radioimmunoassay kits and $\mathrm{PGE}_{2}$ respectively. This work was supported by grants-in-aid for Scientific Research (C) (10670059 and 08670076) from the Ministry of Education, Science, Sports and Culture of Japan to K Y.

\section{References}

1 Nelson RJ, Kriegsfeld LJ, Dawson VL \& Dawson TM. Effects of nitric oxide on neuroendocrine function and behavior. Frontiers in Neuroendocrinology 199718 463-491.

2 Krukoff TL. Central regulation of autonomic function: NO brakes? Clinical and Experimental Pharmacology and Physiology 199825 474-478.

3 Pow DV. NADPH-diaphorase (nitric oxide synthase) staining in the rat supraoptic nucleus is activity-dependent: possible functional implications. Journal of Neuroendocrinology $19924377-$ 380.

4 Kadowaki K, Kishimoto J, Leng G \& Emson PC. Up-regulation of nitric oxide synthase (NOS) gene expression together with NOS activity in the rat hypothalamo-hypophysial system after chronic salt loading: evidence of a neuromodulatory role of nitric oxide in arginine vasopressin and oxytocin secretion. Endocrinology 1994 134 1011-1017.

5 Villar MJ, Ceccatelli S, Ronnqvist M \& Hokfelt T. Nitric oxide synthase increases in hypothalamic magnocellular neurons after salt loading in the rat. An immunohistochemical and in situ hybridization study. Brain Research 1994644 273-281.

6 Yasin S, Costa A, Trainer P, Windle R, Forsling ML \& Grossman A. Nitric oxide modulates the release of vasopressin from rat hypothalamic explants. Endocrinology 1993133 1466-1469.

7 Raber J \& Bloom FE. IL-2 induces vasopressin release from the hypothalamus and the amygdala: role of nitric oxide-mediated signaling. Journal of Neuroscience 199414 6187-6195.
8 Yamamoto T, Kimura T, Ota K, Shoji M, Inoue M, Ohta M et al. Effects of a nitric oxide synthase inhibitor on vasopressin and atrial natriuretic hormone release, thermogenesis and cardiovascular functions in response to interleukin-1 $\beta$ in rats. Tohoku Journal of Experimental Medicine 1994174 59-69.

9 Ota M, Crofton JT, Festavan GT \& Share L. Evidence that nitric oxide can act centrally to stimulate vasopressin release. Neuroendocrinology 199357 955-959.

10 Brody MJ \& Johnson AK. Role of the anteroventral third ventricle region in fluid and electrolyte balance, arterial pressure regulation, and hypertension. Frontiers in Neuroendocrinology 19806 249-292.

11 Johnson AK. The periventricular anteroventral third ventricle $(A V 3 V)$ : its relationship with the subfornical organ and neural systems involved in maintaining body fluid homeostasis. Brain Research Bulletin 198515 595-601.

12 McKinley MJ, McAllen RM, Mendelsohn FAO, Allen AM, Chai SY \& Oldfield BJ. Circumventricular organs: neuroendocrine interfaces between the brain and the hemal milieu. Frontiers in Neuroendocrinology $19901191-127$.

13 Katsuura G, Arimura A, Koves K \& Gottschall PE. Involvement of organum vasculosum of lamina terminalis and preoptic area in interleukin 1 $\beta$-induced ACTH release. American Journal of Physiology 1990258 E163-E171.

14 Matsumura K, Watanabe Y, Onoe H \& Hayaishi O. High density of prostaglandin E2 binding sites in the anterior wall of the third ventricle: a possible site of hyperthermic action. Brain Research $1990533147-151$.

15 Wang $\mathrm{H}$ \& Morris JF. Constitutive nitric oxide synthase in hypothalami of normal and hereditary diabetes insipidus rats and mice: role of nitric oxide in osmotic regulation and its mechanism. Endocrinology 1996137 1745-1751.

16 Zhu B \& Herbert J. Angiotensin II interacts with nitric oxidecyclic GMP pathway in the central control of drinking behaviour: mapping with c-fos and NADPH-diaphorase. Neuroscience 1997 $79543-553$.

17 Calapai G \& Caputi AP. Nitric oxide and drinking behaviour. Regulatory Peptides 199666 117-121.

18 Yamaguchi K, Hama $\mathrm{H}$ \& Watanabe $\mathrm{K}$. Possible roles of prostaglandins in the anteroventral third ventricular region in the hyperosmolality-evoked vasopressin secretion of conscious rats. Experimental Brain Research 1997113 265-272.

19 Yamaguchi K, Hama H \& Watanabe K. Possible participation of prostaglandins generated in the anteroventral third ventricular region in the hypovolemia-induced vasopressin secretion of conscious rats. European Journal of Endocrinology 1998138 206-215.

20 Rettori V, Gimeno M, Lyson K \& McCann SM. Nitric oxide mediates norepinephrine-induced prostaglandin E2 release from the hypothalamus. PNAS 199289 11543-11546.

21 Salvemini D, Misko TP, Masferrer JL, Seibert K, Currie MG \& Needleman P. Nitric oxide activates cyclooxygenase enzymes. PNAS $1993907240-7244$.

22 Amir S, De Blasio E \& English AM. $N^{\mathrm{G}}$-monomethyl-L-arginine co-injection attenuates the thermogenic and hyperthermic effects of E2 prostaglandin microinjection into the anterior hypothalamic preoptic area in rats. Brain Research 1991556 157-160.

23 Liu H, Terrell ML, Summy-Long JY \& Kadekaro M. Drinking and blood pressure responses to central injection of L-NAME in conscious rats. Physiology and Behavior 199659 1137-1145.

24 Moncada S, Palmer RMJ \& Higgs EA. Nitric oxide: physiology, pathophysiology, and pharmacology. Pharmacological Review 199143 109-142.

25 Salter M, Duffy C, Garthwaite I \& Strijbos PJLM. Substantial regional and hemispheric differences in brain nitric oxide synthase inhibition following intracerebroventricular administration of $N^{\mathrm{W}}$-nitro-L-arginine and its methyl ester. Neuropharmacology 199534 639-649.

26 Hoffman WE \& Phillips MI. Regional study of cerebral ventricle sensitive sites to angiotensin II. Brain Research 1976110 313-330.

27 Goyer M, Bui H, Chou L, Evans J, Keil LC \& Reid IA. Effect of inhibition of nitric oxide synthesis on vasopressin secretion in 
conscious rabbits. American Journal of Physiology 1994266 H822-H828.

28 Komaki G, Arimura A \& Koves K. Effect of intravenous injection of IL-1b on PGE2 levels on several brain areas as determined by microdialysis. American Journal of Physiology 1992262 E246E251.

29 Nussler AK, Di Silvio M, Billiar TR, Hoffman RA, Geller DA, Selby R et al. Stimulation of the nitric oxide synthase pathway in human hepatocytes by cytokines and endotoxin. Journal of Experimental Medicine 1992176 261-264.

30 Ishizuka Y, Ishida Y, Jin QH, Shimokawa A, Saita M, Kato K et al. Abdominal vagotomy attenuates interleukin- $\beta$-induced nitric oxide release in the paraventricular nucleus region in conscious rats. Brain Research 1998789 157-161.

31 Lee S \& Rivier C. Interaction between corticotropin-releasing factor and nitric oxide in mediating the response of the rat hypothalamus to immune and non-immune stimuli. Molecular Brain Research 199857 54-62.

32 Bates JN, Baker MT, Guerra R \& Harrison DG. Nitric oxide generation from nitroprusside by vascular tissue. Evidence that reduction of the nitroprusside anion and cyanide loss are required. Biochemical Pharmacology 199142 (Suppl) S157-S165.

33 Sobreviela T, Jaffar S \& Mufson EJ. Tyrosin kinase A, galanin and nitric oxide synthase within basal forebrain neurons in the rat. Neuroscience 199887 447-461.

34 Paxinos G \& Watson C. The Rat Brain in Stereotaxic Coordinates, edn 3. New York: Academic Press, 1997.

35 Cao L, Sun X \& Shen E. Nitric oxide stimulates both the basal and reflex release of vasopressin in anesthetized rats. Neuroscience Letters 1996221 49-52.

36 Yamaguchi K, Koike M \& Hama H. Plasma vasopressin response to peripheral administration of angiotensin in conscious rats. American Journal of Physiology 1985248 R249-R256.

37 Brooks DP, Share L \& Crofton JT. Role of brain prostaglandins in the control of vasopressin secretion in the conscious rat Endocrinology $19861181716-1722$.

38 McKinley MJ. Volume regulation of antidiuretic hormone secretion. In Current Topics in Neuroendocrinology vol. 4, pp 61-100. Eds D Ganten \& D Pfaff. Berlin: Springer-Verlag, 1985.

39 Ramsay DJ, Thrasher TN \& Keil LC. The organum vasculosum laminae terminalis: a critical area for osmoreception. Progress in Brain Research $19836091-98$.

40 Katayama Y. NO releasing agents and their application for biology and medicine. Saishin-Igaku 199752 955-961.

41 Cunningham JT, Nissen R \& Renaud LP. Ibotenate lesions of the diagonal band of Broca attenuate baroreceptor sensitivity of rat supraoptic vasopressin neurons. Journal of Neuroendocrinology 19924 303-309.

42 Sawchenko PE \& Swanson LW. The organization and biochemical specificity of afferent projections to the paraventricular and supraoptic nuclei. Progress in Brain Research 198360 19-29.

43 Versteeg DHG, Petty MA, Bohus B \& de Jong W. The central nervous system and hypertension: the role of catecholamines and neuropeptides. In Handbook of Hypertension, Volume 4: Experimental and Genetic Models of Hypertension, pp 398-430. Ed W de Jong. Amsterdam: Elsevier, 1984.

44 Honda K, Negoro H, Dyball REJ, Higuchi T \& Takano S. The osmoreceptor complex in the rat: evidence for interactions between the supraoptic and other diencephalic nuclei. Journal of Physiology 1990431 225-241.

45 Schuman EM \& Madison DV. Nitric oxide and synaptic function. Annual Review of Neuroscience 199417 153-183.

46 Brooks DP, Share L \& Crofton JT. Central adrenergic control of vasopressin release. Neuroendocrinology $198642416-420$.

47 Iitake K, Share L, Ouchi Y, Crofton JT \& Brooks DP. Central cholinergic control of vasopressin release in conscious rats. American Journal of Physiology 1986251 E146-E150.

48 Yamaguchi $\mathrm{K}$ \& Hama $\mathrm{H}$. Evaluation for roles of periventricular cholinoceptors in vasopressin secretion in response to angiotensin II and an osmotic stimulus. Brain Research $1989496345-350$.

49 Yamaguchi K \& Hama H. Separation of periventricular dopaminergic and alpha-adrenergic systems from the vasopressinsecreting mechanisms activated by prostaglandin D2. Brain Research $1991559261-266$.

50 Yamaguchi K, Hama $\mathrm{H}$ \& Watanabe $\mathrm{K}$. Negligible role of catecholaminergic receptors in the anteroventral third ventricular region in mediating vasopressin-releasing and cardiovascular actions of prostaglandin E2. Experimental Brain Research 1999 $129532-540$.

51 Bogdanov MB \& Wurtman RJ. Possible involvement of nitric oxide in NMDA-induced glutamate release in the rat striatum: an in vivo microdialysis study. Neuroscience Letters 1997221 197201.

52 Brann DW \& Mahesh VB. Excitatory amino acids: function and significance in reproduction and neuroendocrine regulation. Frontiers in Neuroendocrinology 199415 3-49.

Received 22 March 2000

Accepted 30 June 2000 